\title{
O ENSINO SUPERIOR NA QUALIFICAÇÃO DE COMPETÊNCIAS EM PROTEÇÃO CIVIL - UM MODELO METODOLÓGICO DE PESQUISA
}

\author{
Manuel Ribeiro ${ }^{1}$, Ana Paula Oliveira², Paulo Gil Martins ${ }^{3}$ \\ Escola de Tecnologias e Engenharia do Instituto Superior de Educação e Ciências de Lisboa (ISEC Lisboa), Portugal. \\ 1'manuel.ribeiro@iseclisboa.pt, ${ }^{2}$ ana.oliveira@iseclisboa.pt, ${ }^{3}$ gil.martins@iseclisboa.pt
}

\begin{abstract}
Resumo. O conhecimento dos processos e mecanismos educativos da formação em Proteção Civil no ensino superior em Portugal constitui o quadro referencial deste artigo. Centrado na análise dos cursos em Proteção Civil do ISEC Lisboa, o estudo procura medir os impactos decorrentes nas atividades profissionais dos alunos graduados nesta formação académica. Metodologicamente, o trabalho de investigação assenta numa análise extensiva, privilegiando, de forma integrada, métodos qualitativos, avaliativos das perceções e representações sociais de alunos e instituições empregadoras, e informação estatística de caraterização sociográfica, socioeconómica e sócio funcional de uma amostra representativa do universo de estudo. Como resultados expectáveis, pretende-se desenvolver um modelo teórico-analítico, enquadrador e comparativo de uma apreciação profissional das habilitações e competências dos diplomados. Conhecer os pontos fortes, e menos fortes, que os profissionais com qualificações adquiridas nestes cursos apresentam, nesta área vital da segurança das pessoas, bens, infraestruturas vitais e ambiente, é a finalidade desta investigação.
\end{abstract}

Palavras-chave: Proteção Civil; Modelo Teórico-Analítico; Ensino Superior; Competências Científicas; Qualificações Profissionais.

\section{HIGHER EDUCATION IN QUALIFYING CIVIL PROTECTION SKILLS - A METHODOLOGICAL} RESEARCH MODEL

Abstract. The knowledge of the educational processes and mechanisms resulting from training in Civil Protection in higher education in Portugal constitutes the referential framework of this article. Centered on the analysis of Civil Protection courses at ISEC Lisboa, the study seeks to measure the impacts on the professional activities of the graduated students. Methodologically, the research work is based on extensive analysis, favoring, in an integrated way, qualitative methods, evaluating the perceptions and social representations of students and employing institutions, and statistical information of sociographic, socioeconomic and socio-functional character of a representative sample of the study universe. As expected, results, it is intended to develop a theoretical-analytical model, framing and comparing a professional appraisal of the qualifications and skills of graduates. Knowing the strengths, and weaknesses, that the professionals with qualifications acquired in these courses present, in this vital area of the safety of people, goods, vital infrastructure and environment, is the purpose of this investigation.

Keywords: Civil Protection; Theoretical-Analytical Model; Higher Education; Scientific Competences; Professional Qualifications.

\section{INTRODUÇÃO}

O conhecimento dos processos e mecanismos educativos da formação no ensino superior em Portugal têm, nos últimos anos, sido apontados como estando por detrás dos resultados 
que evidenciam uma das melhores e mais bem preparadas gerações de estudantes, constituindo o quadro referencial deste trabalho investigativo.

A necessidade de profissionais habilitados no domínio da segurança em Proteção Civil (PC) conduziu a que, em 2004, fossem criados em Portugal cursos específicos nesta área de atividade e de conhecimento técnico-científico. Após um primeiro registo, onde a procura ultrapassou em larga medida as ofertas formativas existentes à época, este tipo de formação veio a conhecer uma fase de relativa estagnação, por inadequação do quadro legislativo existente. O Instituto Superior de Educação e Ciências de Lisboa (ISEC Lisboa), desde 2007, apostou nesta dimensão formativa, ao nível da licenciatura, abrindo, posteriormente, em 2011, o primeiro mestrado na área. Contrariamente a outros estabelecimentos de ensino superior, públicos e privados, que cancelaram as suas ofertas formativas, o ISEC Lisboa veio a afirmar-se como instituição de referência neste âmbito, mantendo, uma continuidade que o situa numa das escolas mais procuradas por alunos neste domínio formativo.

É neste contexto que se coloca como questão de partida deste estudo, a interrogação de saber se as formações, ao nível da licenciatura de Engenharia de Proteção Civil (LEPC) e do mestrado em Riscos e Proteção Civil (MRPC) do ISEC Lisboa, têm contribuído para a melhoria da qualificação dos agentes de PC e dos cidadãos em geral. Dado o enquadramento de base, considerou-se lançar o presente trabalho, numa ótica tendente a monitorizar e avaliar a pertinência formativa, educativa e profissional dos cursos em análise e, daí decorrente, equacionar a eventual introdução de alterações e atualizações que melhor consubstanciem as expetativas e representações, quer dos elementos licenciados, quer das entidades empregadoras.

Esta pesquisa assume como objetivo geral o estudo do impacto dos cursos em PC do ISEC Lisboa nas atividades profissionais relacionadas com esta área de segurança. Para o cumprimento deste objetivo, definiram-se como objetivos específicos os seguintes:

- Elaborar um modelo metodológico de análise;

- Avaliar o aproveitamento escolar, qualificações e competências dos alunos;

- Identificar e recensear os pontos fortes e fracos com os curricula dos cursos;

- Analisar a perceção sobre os processos educativos relativamente às exigências reais do sistema de PC; 
- Apreciar o impacto socioprofissional nas instituições empregadoras com alunos.

A estrutura deste artigo (Figura 1), para além desta nota introdutória, apresenta num segundo ponto, um breve enquadramento da PC, discutindo alguns dos momentos marcantes da sua evolução até à atualidade. O terceiro ponto incide na apresentação da metodologia de suporte e de orientação do estudo. Por último, e num quarto ponto, discutem-se, os resultados esperados, apresentando-se linhas de desenvolvimento subsequentes.

As formações, ao nível da Licenciatura de Engenharia de Proteção Civil e do Mestrado em Riscos e Proteção Civil do ISEC Lisboa, têm contribuído para a melhoria da qualificação dos agentes de proteção civil e dos cidadãos em geral?

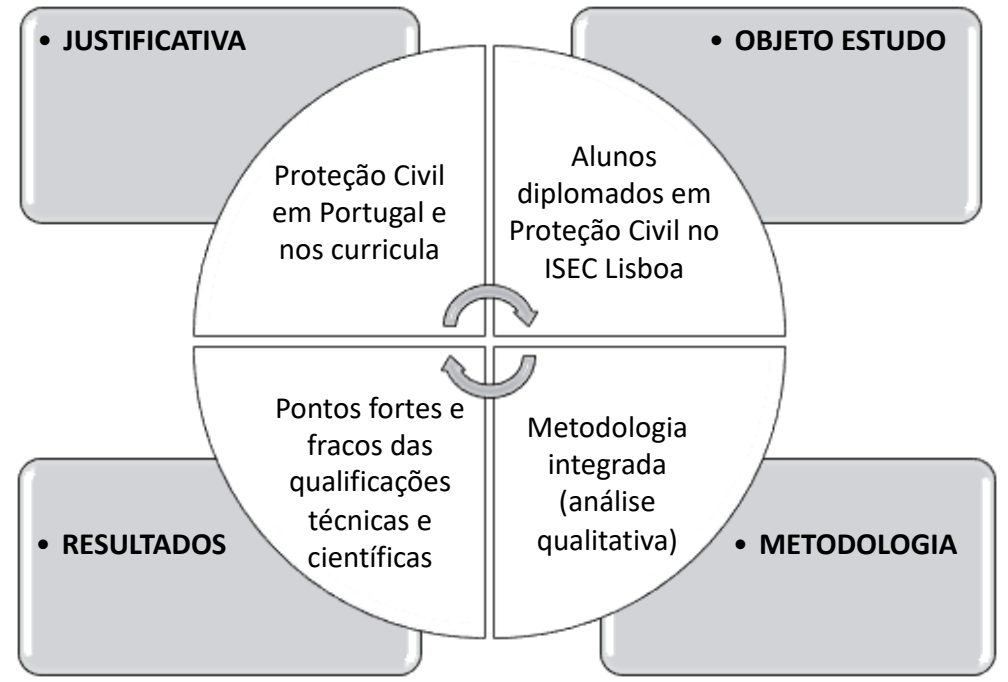

Figura 1. Estrutura conceptual do artigo.

\section{A PROTEÇÃO CIVIL COMO DOMÍNIO TÉCNICO-CIENTÍFICO E PROFISSIONAL}

\subsection{Evolução em Portugal}

A evolução da PC em Portugal, enquanto atividade técnica e científica, tem acompanhando de perto as respostas, que o sistema nacional tem dado às situações mais mediáticas de acidentes graves e catástrofes que têm afetado o território nacional. 
Procurando não retroceder demasiado numa leitura cronológica, saliente-se o incontornável Incêndio do Chiado (Lisboa), de agosto de 1988, como um dos marcos fundamentais desse desenvolvimento. Como salientam Silva \& Pedro (2016), "deste incêndio derivou uma série de estudos, publicações técnicas e conferências no sentido de se desenvolver em Portugal uma maior cultura de prevenção e segurança no que tange à problemática dos incêndios urbanos (...)" (p. 194).

Um outro acontecimento marcante constituiu o ano de 2003, com a ocorrência de incêndios florestais em Portugal, com cerca de 300 mil hectares de área ardida, e mais de 20 vítimas mortais, cumulativamente com uma importante onda de calor, onde terão perecido, apenas neste último caso, para cima de 2300 pessoas. Os incêndios florestais fizeram despoletar um conjunto de preocupações, que viriam a dar origem ao célebre Livro Branco de Incêndios Florestais (MAI, 2003), onde se apresentavam, um conjunto de medidas a implementar na melhoria e aumento do conhecimento técnico e científico para lidar com esse tipo de fenómenos desastrosos.

O ano de 2005 virá a constituir uma viragem em todo o edifício da PC e, novamente, por motivos relacionados com os incêndios florestais desse ano. Altera-se a arquitetura legislativa do sistema, procurando uma estruturação mais próxima de uma conceção fundamental com o incontornável ciclo das catástrofes. Esta assunção construtiva virá a tornar-se uma verdadeira rutura epistemológica.

O corolário de todo este processo evolutivo, seriam os incêndios florestais de 2017 em Portugal, com o seu elevado número de vítimas mortais e a destruição de enormes áreas rurais e florestais. No relatório da então criada Comissão Técnica Independente será dada relevância especial ao papel que o conhecimento científico deve ter para lidar com estes acontecimentos desastrosos.

Os problemas decorrentes da PC, contudo, não se circunscrevem apenas aos que se relacionam com os incêndios florestais. Para além desse tipo de riscos, outros, de cariz natural, tecnológico e misto constituem preocupações acrescidas do universo nacional e internacional. A recente e atual pandemia do Covid19, embora localizada no âmbito de uma gestão de saúde pública, é um exemplo da importância de uma atuação por parte do sistema de PC, exigindo, técnicos e profissionais habilitados para gerir as diferentes implicações daqui resultantes. 


\subsection{O ISEC Lisboa no ensino de Proteção Civil}

A PC é hoje uma área do saber, agregadora do conhecimento de múltiplas ciências, que permite organizar, numa abordagem global e sistémica, as suas inter-relações tendo em vista a tomada de decisões fundamentadas, estimulando e aprofundando o conhecimento avançado, nomeadamente sobre liderança, comportamento humano, gestão da comunicação, do risco e dos desastres.É neste contexto que o ISEC Lisboa se posiciona relativamente ao ensino em $\mathrm{PC}$, de modo a que esta área de atividade se possa orientar com base nas necessidades da sociedade.

O ISEC Lisboa aposta numa formação de acentuado cariz profissionalizante, cumulativamente com uma investigação aplicada e colaborativa, tendente à produção de soluções e à criação de valor transferíveis para as empresas e organizações. Sublinhe-se que para o ISEC Lisboa, a discussão e a reflexão sobre as diferentes temáticas em torno da PC são uma constante iniludível no seu quotidiano.

Os professores, alunos, especialistas, muitos dos quais profissionais com larga experiência no setor, procuram diariamente estudar e refletir sobre as questões várias da PC, nas suas diferentes valências. Destaca-se a investigação científica e a produção de novos conhecimentos nesta área, mas sobretudo a integração do conhecimento científico na praxis diária dos agentes da PC e a incorporação desse conhecimento no apoio à tomada de decisão.

O projeto científico e pedagógico do ISEC Lisboa para o ensino em $\mathrm{PC}$, para além da sua componente intrinsecamente técnica, estrutura-se também numa formação global de cidadania que inclui a formação cívica, ética, deontológica e cultural.Este conjunto de ferramentas de ensino, resulta de uma análise cuidada e da reflexão partilhada com diversas personalidades e entidades, incluindo profissionais e estudantes, com natural enfoque para os quadros das instituições de segurança e PC, seja das organizações de âmbito nacional, seja as de âmbitos regional, distrital e municipal.

É num quadro contextualizador da oferta educativa, formativa e profissional do ISEC Lisboa, que se procura, no presente trabalho de investigação, verificar, confirmando ou infirmando as hipóteses que se apresentam no ponto seguinte, a sua constituição em mais valias e valores acrescentados no mercado de trabalho da segurança e da PC. 


\section{METODOLOGIA}

A Figura 2 sistematiza o modelo metodológico de análise, nas suas 5 fases.

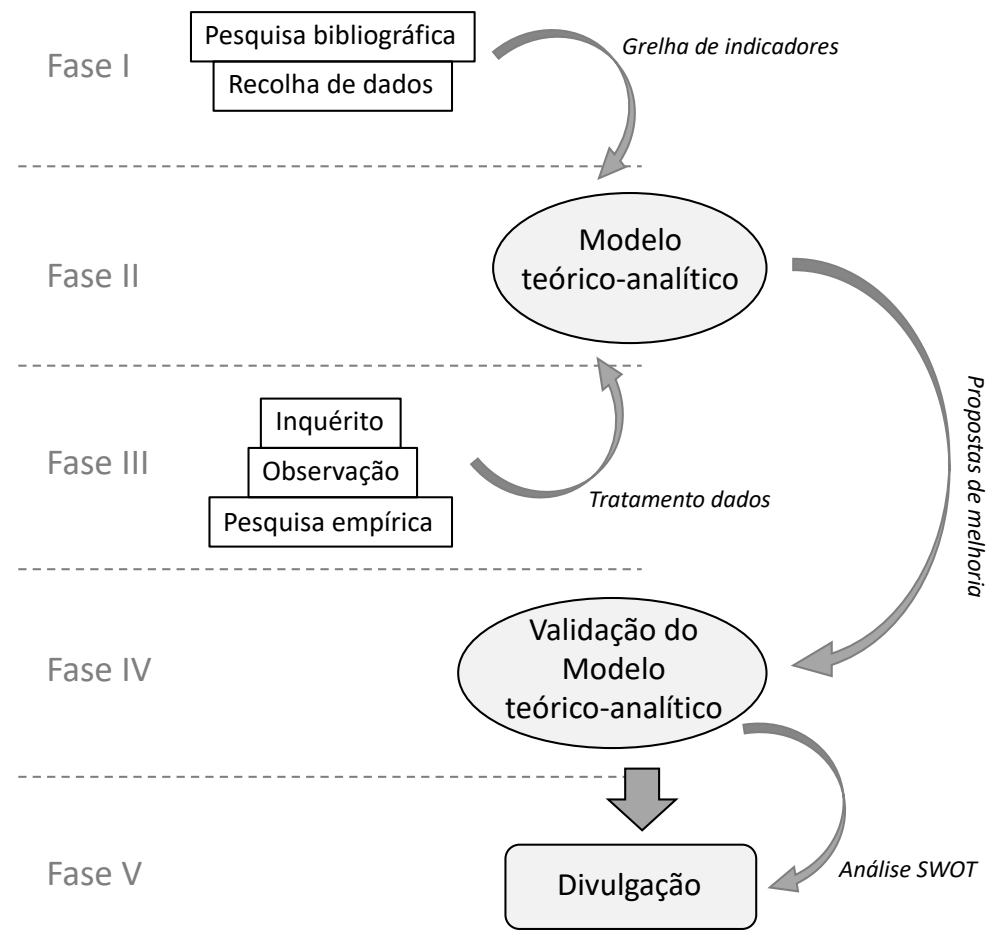

Figura 2. Modelo metodológico da pesquisa.

Pormenorizando os principais procedimentos, e após uma análise exploratória e identificativa da problemática de análise (Fase I; Fig. 2), desenvolver-se-á uma proposta teórico-analítica, centrada em torno de uma reflexão destes processos e mecanismos educativos, evidenciando um quadro epistemológico que se constitua em suporte elucidativo dos referenciais que Ihe conferem consistência explicativa (Fase II; Fig. 2). Com base na inerente, e indispensável, revisão da literatura, e respetiva análise documental de estudos e projetos sobre a matéria, procurar-se-á observar registos comparativos, e singulares, de suporte à pesquisa a efetuar.

Para a realização deste trabalho, torna-se metodologicamente indispensável formular a orientação que sustentará o desenvolvimento subsequente da pesquisa. Assim, e na sequência da definição apresentada como interrogação de partida, colocam-se agora, e de 
modo a assegurar a imprescindível garantia da exequibilidade do processo investigativo, as seguintes hipóteses teóricas de trabalho:

a) A LEPC e o MRPC potenciam fatores positivos na formação superior dos alunos repercutindo-se na sua qualificação técnico-profissional com óbvias mais valias para as instituições onde desenvolvem as suas atividades;

b) A adequação dos curricula, quer da licenciatura, quer do mestrado, encontram-se, cabalmente, adequados ao mercado de trabalho que procuram formação nesta área;

c) As representações sociais das instituições e organismos empregadores de licenciados e mestres com formação nestas áreas do ISEC Lisboa, são, de modo geral, positivas em relação aos conhecimentos técnicos e científicos adquiridos pelos colaboradores com estas credenciações.

A pesquisa (Fase III; Figura 2), centrada em dimensões analíticas de cunho qualitativo, procura avaliar perceções relacionadas com a formação disponibilizada e alcançada pelos alunos do ISEC Lisboa, incluindo, as representações sociais das entidades nas quais esses profissionais se inserem. De todo o modo, não se deixará de cruzar os inerentes dados de caraterização sociográfica e socio funcional, de forma a não omitir as eventuais correlações existentes neste domínio de análise.

Como moldura enquadradora do projeto (Fase I; Fig. 2), e num levantamento inicial sistematizado da informação, através da consulta dos registos documentais e estatísticos existentes, o público alvo do universo considerado reporta-se a:

a) 295 alunos que iniciaram a LEPC, tendo concluído os estudos académicos 133 , o que corresponde a uma percentagem de $45,1 \%$ de êxito alcançado;

b) 127 alunos inscritos no MRPC, dos quais apresentaram as respetivas dissertações, concluindo com sucesso esta etapa, 38 , representando $29,9 \%$ do total.

Define-se, para tal, uma grelha analítica com indicadores selecionados, caraterizadores de um conjunto de variáveis comparativas e explicativas do universo a abordar. Neste domínio, são consideradas quatro grandes dimensões analíticas:

a) Caraterização sociográfica dos alunos, decorrentes de indicadores sociodemográficos, sócio estruturais e socioeconómicos;

b) Definição do percurso letivo e académico, com referenciais centrados na duração da frequência dos cursos, opções temáticas dos projetos apresentados e respetivas avaliações finais;

c) Medição, através de inquéritos estruturados, das opiniões e perceções relacionadas com os cursos, aplicando-se escalas de Likert para avaliação dos graus de satisfação/insatisfação das várias componentes sistémicas do processo educacional frequentado;

d) Apreciação das representações sociais de empregadores e chefias dos profissionais saídos dos cursos de formação, referenciada através de análise de conteúdo dos respetivos discursos e narrativas. 
A recolha dos dados é efetuada de forma sistematizada, com parâmetros oscilando entre os elementos de caraterização sociográfica dos alunos, percurso letivo e profissional de entrada, situação na profissão após conclusão da licenciatura/mestrado, realçando, no domínio da formação, as opções sobre os temas finais escolhidos, e respetiva classificação alcançada. Privilegiando uma análise de índole mais intensiva, embora suportada numa amostra selecionada com base no universo definido, será também aplicado um questionário estruturado onde se contemple variáveis decorrentes das perceções dos alunos sobre o curricula, modelos e métodos formativos, terminando com auscultações sobre recomendações e indicações de melhoria, nas suas respetivas opiniões (Fase III; Fig. 2). Constitui, ainda, âmbito do estudo, avaliar comparativamente, a evolução alcançada entre o momento de entrada e o pós credenciação, licenciatura ou mestrado, na vida socioprofissional dos alunos. Nesta dimensão, encontra-se equacionada a aplicação de um levantamento e aplicação de inquérito, através de questionário, ou entrevista diretiva, às entidades empregadoras, de modo a entender as mais valias e o valor acrescentado decorrente da formação superior frequentada.

Após a respetiva pesquisa empírica cruzam-se os dados alcançados, confrontando-os e validando-os com o modelo teórico analítico (Fase IV; Figura 2).

\section{RESULTADOS E CONCLUSÕES ESPERADAS}

Encontrando-se o trabalho ainda numa fase inicial, torna-se prematuro apresentar quaisquer resultados que possam constituir-se em leituras informativas e identificadoras das tendências existentes sobre o nível e grau de pertinência dos cursos em análise, face aos objetivos traçados. De qualquer modo, uma primeira ilação é possível, desde logo, retirar. A procura por estes cursos de formação no ISEC Lisboa, apesar de algumas oscilações pontuais, tem-se mantido estável, registando, inclusive, patamares de crescimento que, embora ligeiros, permitem aferir, em tese, dois tipos, interligados, de cenários. Por um lado, uma procura resultante do interesse que distintos nichos do mercado de trabalho apresentam por estas áreas, consideradas como altamente deficitárias em termos de conhecimento e competências técnicas, profissionais e científicas. Por outro lado, a propalada aprendizagem ao longo da vida, na qual os indivíduos procuram melhorar e aumentar os seus conhecimentos, mesmo, em alguns dos casos, sem tradução visível em formas de progressão profissional nos contextos onde se encontram inseridos. 
Embora constituindo uma "tarefa de todos para todos", o exercício das atividades de PC encerra, uma tecnicidade e um conhecimento que apenas se encontra ao alcance de quem possui habilitações e formação específica para o seu desempenho. O reforço das competências institucionais e profissionais é, assim, uma finalidade indispensável no caminho de uma consolidação da formação dos agentes e atores da PC, habilitando-os ao tratamento adequado das matérias respeitantes a esta área, designadamente no planeamento, na gestão e nas operações de emergência.

Tratando-se de uma incursão avaliativa de modelos de ensino, é expectável, que os resultados a alcançar, permitam definir linhas de orientação e de melhoria dos curricula dos cursos, adaptados às realidades que alimentam e, concomitantemente, possam repercutir uma maior proximidade entre o saber académico e científico e a prática técnica e operacional.

\section{REFERÊNCIAS}

MAI (2003). Livro Branco dos Incêndios Florestais Ocorridos no Verão de 2003, Gabinete do Ministro, Lisboa.

Silva, C. \& Pedro, M. (2016). Incêndio do Chiado. Um olhar técnico-operacional. Câmara Municipal de Lisboa, Imprensa Municipal, Lisboa. 